\title{
MERCADO DE FRUTAS FRESCAS NO MUNICÍPIO DE MINEIROS-GO
}

\author{
MAURO BRASIL DIAS TOFANELLI², MARILAINE DE SÁ FERNANDES ${ }^{3}$, NÚBIA SOUSA CARRIJO ${ }^{4}$, \\ OSCAR BARBOSA MARTINS FILHO
}

RESUMO - A eficiência na comercialização de frutas necessita de estudos constantes nos mercados para fornecer informações que possam servir de suporte à elaboração de estratégias e execuções de ações para melhorias do contexto mercadológico. O presente trabalho teve como objetivo realizar levantamento do mercado de frutas frescas no município de Mineiros-GO, a fim de fornecer informações de mercado que possam auxiliar em ações específicas ao setor. Para isso, foram realizadas pesquisas em estabelecimentos comerciais (equipamentos varejistas: supermercados, quitandas/sacolões e feira-livre), entre dezembro de 2005 e janeiro de 2006 , mediante aplicação de questionários em cada equipamento. Dentre as frutas relacionadas pelos resultados da pesquisa, a laranja foi a que apresentou o maior volume de comercialização $\left(7.196 \mathrm{~kg} \mathrm{semana}^{-1}\right)$, seguida da banana $\left(2.812 \mathrm{~kg} \mathrm{semana}^{-1}\right)$ e maçã $\left(2.526 \mathrm{~kg} \mathrm{semana}^{-}\right.$ $\left.{ }^{1}\right)$. Os resultados demonstraram que os supermercados e as quitandas são os principais responsáveis pelo comércio de frutas em Mineiros. A deficiência na produção local de frutas em Mineiros pôde ser sugerida quando ficou demonstrado que 93,3\% dos estabelecimentos de frutas comercializadas neste município são abastecidos pelos Ceasas e apenas 6,7\% por produtores locais.

Termos para indexação: produtos frutícolas, comercialização, mercado, fruticultura.

\section{FRUIT MARKETING IN MINEIROS, GOIÁS STATE, BRAZIL}

\begin{abstract}
The efficiency in the commercialization of fruits needs constant studies in the markets to supply information that can serve of support to the elaboration of strategies and executions of action for improvements of the marketing context. The present work had as objective to carry through survey of the market of fresh fruit in the city of Mineiros (State of Goiás, Brazil) in order to supply market information that can assist in specific actions to the sector. For this, research in commercial establishments had been carried through. For this, retail equipment had been carried through research in commercial establishments (supermarkets, grocery stores/ retail shops and street market) in December 2005 to January 2006 by means of application of questionnaires in each equipment. Amongst the fruits related for the results of the research, the orange was the one that presented the biggest volume of commercialization $\left(7,196 \mathrm{~kg}\right.$ week $\left.{ }^{-1}\right)$, followed of the banana $\left(2,812 \mathrm{~kg}\right.$ week $\left.^{-1}\right)$ and apple $\left(2,526 \mathrm{~kg} \mathrm{week}^{-1}\right)$. The results had demonstrated that the supermarkets and grocery stores are main the responsible ones for the commerce of fruits in Mineiros. The deficiency in the local production of fruits in Mineiros could be suggested when he was established that $93.3 \%$ of the fruits commercialized in this city are supplied by the Ceasas and only $6.7 \%$ for local producers.
\end{abstract}

Index terms: Fruits, commercialization, market, fruticulture.

\section{INTRODUÇÃO}

Frutas frescas são uma das excelentes alternativas para o fornecimento de vitaminas, sais minerais e carboidratos na alimentação humana. Porém, nem sempre o consumo é suficientemente adequado às necessidades diárias, seja pela má educação alimentar, seja por dificuldades no sistema de comercialização dos produtos frutícolas (venda ' compra). Dentre estas, citam-se como exemplo os preços de venda ao consumidor de muitas frutas nos mercados que, devido ao baixo poder aquisitivo do brasileiro, muitas vezes não chegam às mesas das residências, contribuindo para o baixo índice de consumo per capita de frutas no Brasil (24,5 kg habitante ${ }^{-1}$ ano $^{-1}$ para o período de 2002-2003);(IBGE, 2006).

Há uma forte relação entre renda e consumo de frutas e existem expectativas para que o consumo cresça com o passar dos anos (Souza, 2006; Ramos et al., 2002), porém outra estratégia para fortalecer o mercado local de frutas, é incentivar a exploração de frutíferas mediante a implantação de pomares nas imediações de uma determinada região em que a fruticultura seja incipiente, $o$ que poderia contribuir para diminuir os preços ao consumidor e facilitar o processo de transporte e comercialização (menores distâncias). Sobretudo, as estratégias, ações e soluções de muitos dos problemas no contexto do mercado de frutas seriam facilitadas com o conhecimento do complexo de comercialização destes produtos mediante um estudo mercadológico que forneceria informações, como origem das frutas, preferência do consumidor, sazonalidade de preços, relação oferta ' procura (safra/entressafra) e volume comercializado.

Silva et al. (2003) destacaram a importância de se ter

\footnotetext{
1 (Trabalho 99-06). Recebido em: 21-07-2006. Aceito para publicação: 19-04-2007. Apoio Financ: Fimes

2 Eng $^{\circ}$ Agrônomo, Prof. Adjunto, Doutor, ICA/Faculdades Integradas de Mineiros/Fimes. Endereço: Rua 22, s/n, Setor Aeroporto, Caixa Postal 104, CEP 75830-000, Mineiros-GO. Email: maurobrasil@fimes.edu.br marilaine@fimes.edu.br

${ }^{3}$ Eng ${ }^{a}$ Agrônoma, Profa. Assistente, Mestre, ICA/Faculdades Integradas de Mineiros/Fimes. Coordenadora do Instituto de Dados Estatísticos e de Pesquisas Sócios-Econômicas - Indep/Fimes. Email: marilaine@fimes.edu.br

${ }^{4}$ Acadêmicos do Curso de Engenharia Florestal, bolsistas do Indep/Fimes. Email: florestabuba@yahoo.com.br; oscar7676@yahoo.com.br
} 
conhecimento do estudo de comercialização, pois mencionaram que a organização mais eficiente da cadeia depende das características do produto e do mercado, e que um dos fatores que contribuem para uma postura cooperativa, é a transparência nas relações, onde informações sobre a participação de cada elo sejam do conhecimento de todos. Fagundes \& Yamanishi (2002) também afirmaram que é de fundamental importância conhecer alguns fatores que contribuem para a formação do processo para que sejam adotadas técnicas que visem a melhorar o sistema de comercialização de produtos vegetais.

Estudar periodicamente os preços de compra e venda, bem como a margem de comercialização, é uma das ações que possibilitaria ao varejista, por exemplo, manipular conscientemente os preços para aumentar as vendas de determinado produto e incentivar o seu maior consumo mediante preços promocionais embasados no conhecimento obtido, sem, contudo, provocar risco de diminuição no lucro de venda. Para Lourenzani e Silva (2004), a criação de preços promocionais é uma estratégia de marketing e uma excelente forma de atrair o consumidor para aumentar as vendas no setor varejista.

O Estado de Goiás ainda apresenta uma tímida expressão no cenário nacional de produção de frutas, pois produziu menos de 400 mil toneladas em 2004 e ocupou apenas a $16^{\mathrm{a}}$ posição no ranking dos estados brasileiros (IBGE, 2006). O município de Mineiros, localizado na região sudoeste de Goiás, não é diferente, não tem tradição no agronegócio da fruticultura e depende basicamente do fornecimento de frutas vindas de outras regiões do próprio Estado e até mesmo de outros estados brasileiros, o que contribui para elevar os custos e prejudicar a qualidade póscolheita das frutas.

Não há relatos sobre o mercado local de frutas, nem os varejistas e fruticultores locais têm conhecimento do que é consumido de frutas no município de Mineiros, fato que dificulta as ações de fortalecimento do setor frutícola produtivo e comercial. Informações mercadológicas são consideradas básicas para o desenvolvimento de programas em fruticultura. Silva et al. (2003) destacaram que é de fundamental importância a coordenação e o monitoramento dos agentes da produção, agroindústria, atacado, varejo e consumidor final para os setores agroalimentares e que a organização mais eficiente nessas cadeias depende das características do produto e do mercado.

Este trabalho teve como objetivo conhecer o mercado de frutas em Mineiros (GO) para fornecer informações sobre o seu complexo de comercialização para servir de suporte às futuras ações de estruturação do setor comercial da região.

\section{MATERIAL E MÉTODOS}

A pesquisa foi realizada no município de Mineiros, localizado no sudoeste do Estado de Goiás, às margens da rodovia BR-364, a $108 \mathrm{~km}$ a leste do município de Jataí-GO, e a $90 \mathrm{~km}$ a oeste do município de Santa Rita do Araguaia-GO (divisa com o Estado do Mato Grosso), sendo as capitais estaduais mais próximas : Goiânia-GO, a 420 km e Cuiabá-MT, a 500 km. Mineiros possui uma população de 43.961 pessoas, conforme estimativa para julho de 2005 do Instituto Brasileiro de Geografia e Estatística
(IBGE, 2006). Apresenta solos predominantemente arenosos e clima definido basicamente por duas estações: uma seca, com temperaturas amenas, e a outra chuvosa, com temperaturas elevadas, apresentando como predominância vegetacional o Cerrado. É um município que tem como atividade principal a agropecuária, baseada na exploração de culturas anuais, como soja e milho, e da pecuária de corte e leite.

Os estabelecimentos responsáveis pela comercialização de produtos hortifrutigranjeiros em Mineiros se resumem em supermercados, quitandas/sacolões e feira-livre; classificação esta seguindo proposta de Barros et al. (1978), citados por Silva et al. (2003). Sendo assim, o universo adotado para estudo foi composto por equipamentos varejistas, sendo oito supermercados de médio a pequeno porte, duas quitandas (conhecidas localmente como "frutarias") e uma feira-livre. Devido a esta apresentar-se pouco expressiva no mercado local de frutas (baixo volume e pouca diversidade), efetuou-se entrevista a cada feirante de modo que os dados obtidos em toda feira-livre pudessem ser agrupados e representativos, ou seja, a soma das vendas em uma feira.

A metodologia utilizada foi mediante visitação in loco para aplicação de questionário nos equipamentos varejistas, no período compreendido entre dezembro de 2005 e janeiro de 2006 , por meio de entrevistas realizadas com os encarregados do setor de hortifruti (no caso dos supermercados), com os proprietários das quitandas/sacolões e diretamente com os feirantes nas bancas ou barracas de venda na feira-livre. $\mathrm{O}$ questionário foi aplicado pela equipe de entrevistadores do Instituto de Dados Estatísticos e de Pesquisas Socioeconômicas (Indep) pertencente às Faculdades Integradas de Mineiros, mantidas pela Fundação Integrada Municipal de Ensino Superior (Fimes) de Mineiros-GO.

O questionário foi constituído de questões (perguntas ao entrevistado) para obter as seguintes informações: a) Frutas comercializadas semanalmente em maior volume; b) Fornecedores das principais frutas comercializadas, e c) Preço médio de compra e venda. A partir dos preços obtidos, foi calculada a margem de comercialização do varejista, utilizando-se da expressão proposta

por Bueno et al. (1999): $M v=\frac{P v v-P v a}{P v v} \times 100$, onde: $\mathrm{Mv}=$ margem do varejista; $\mathrm{Pvv}=$ preço de venda no varejo, e Pva $=$ preço de venda no atacado. Calculou-se também a margem de lucro bruto no varejo mediante a seguinte expressão:

$$
M l b=\frac{P v v-P v a}{P v a} \times 100, \text { onde } \mathrm{Mlb}=\text { margem de lucro bruto. }
$$

Os preços de varejo (venda) e de atacado (compra) adotados para cálculos foram obtidos pela média simples dos valores, para cada fruta, declarados pelos varejistas entrevistados, e corrigidos pelo Índice Geral de Preços - IGP-DI, para valores de maio de 2006, conforme dados do Instituto Brasileiro de Economia (IBRE, 2006).

\section{RESULTADOS E DISCUSSÃO}

A pesquisa nos equipamentos varejistas revelou que as 
frutas mais consumidas semanalmente em Mineiros são: laranja (7.196 kg), seguida por maçã (2.812 kg), banana (2.526 kg), abacaxi $(1.935 \mathrm{~kg})$ e mamão $(1.473 \mathrm{~kg})$ (Tabela 1$)$. Há uma tendência de preferência dos mineirenses por frutas tropicais e subtropicais, com exceção da maçã, as quais ocuparam as seis primeiras posições no ranking de volume comercializado pelo varejo. Uma explicação para este fato talvez seja a própria tradição da população local em consumir frutas mais comuns à região, pois frutas produzidas em regiões mais distantes, como nectarina, pêra e uva, são pouco consumidas pelos mineirenses. Outro fator que pôde ter contribuído, foi o fato de as entrevistas terem sido realizadas no início do verão brasileiro, onde a disponibilidade sazonal proporciona maior oferta de frutas tropicais e subtropicais nesta época. Aliado a isso, a preferência por determinadas frutas pelos consumidores pode ter sido influenciada pelos preços nos equipamentos varejistas, pois observou-se que, para nectarina, pêra e uva, foram registrados os maiores preços ao consumidor (Tabela 2) e foram classificadas entre as de menor consumo, ou seja, quanto maior o preço, menor o consumo. Esta relação inversa entre preço e consumo pôde ser confirmada pelo efeito significativo da correlação negativa entre os dois parâmetros (Tabela 3). Conforme Rangel et al. (2003), o preço tem uma relação fortíssima com o maior ou menor consumo de frutas pela população, pois estudaram o mercado de mamão em Brasília-DF, e observaram que a redução no consumo desta fruta poderia estar sendo influenciada pelo consumo de outras frutas com preços mais acessíveis. Estes autores mencionaram ainda que o preço é um dos principais critérios adotados pelos consumidores na decisão de qual fruta consumir.

Um fator que contribui para que as frutas de clima temperado apresentassem preços menos acessíveis ao consumidor, é a distância dos deslocamentos devido serem oriundas de regiões distantes do sudoeste de Goiás, como São Paulo e Estados do Sul do Brasil. Já existem algumas iniciativas de se trazer para o Estado de Goiás, principalmente para as regiões sudoeste e sul deste Estado, espécies frutíferas de clima temperado melhoradas e menos exigentes em condições edafoclimáticas, particularmente em relação à exigência de frio. Estes materiais têm sido pesquisados e ainda estão em estágio de campo para verificar a adaptação e viabilidade de cultivo das frutíferas temperadas nas condições de Cerrado (Diário da Manhã, 2004).

Os preços praticados nos equipamentos varejistas têm uma forte correlação positiva com os preços oferecidos pelos atacados (Tabela 3). Sobretudo a margem de comercialização pode ser melhor trabalhada para estabelecer menor discrepância entre elas, pois variaram de $28,8 \%$ a $61,7 \%$ (Tabela 2 ), quando se objetiva administrar os preços para elevar as vendas de determinadas frutas, sem, contudo, causar riscos de queda no rendimento financeiro do varejo. Se há no mercado varejista uma fruta comercializada em pequeno volume e que apresente elevada margem, e outra fruta comercializada em grande volume, mas sob baixa margem, poder-se-iam manipular os preços, embasado-se na equivalência entre as margens de comercialização, de maneira que a fruta menos consumida tivesse preço promocional para incentivar a sua venda, e a fruta vendida em maior volume obtivesse imperceptível aumento para manter a rentabilidade do varejo. Bueno et al. (1999) estudaram a sazonalidade de frutos cítricos em Lavras-MG, entre setembro de 1993 e abril de 1995, e também observaram que as margens de comercialização não foram equilibradas no período de estudo e que estas oscilavam ainda mais devido à tendência de manutenção dos preços no varejo mesmo com a sazonalidade destes no atacado. Analisando a margem de lucro bruto, observa-se uma discrepância ainda maior entre os valores (20,0 a 161,2\%), o que reforça a teoria de que há carência de estudos mais aprofundados de todo contexto mercadológico para se evitar tal situação.

A maior participação na comercialização de frutas frescas em Mineiros, no agregado, foi dos supermercados (63,5\%), porém, proporcionalmente, as quitandas têm uma marcante participação, pois, considerando a média, obtiveram $61,5 \%$ de participação. As quitandas (sacolões) são estabelecimentos comerciais especializados em hortifrutigranjeiros (Silva et al., 2003), e os consumidores, muitas vezes, preferem buscar os seus produtos nestes locais à procura de qualidade e diversidade.

A laranja foi responsável por $40,1 \%$ do consumo relativo às outras frutas, e essa predominância pode ser explicada, em boa parte, pelo fornecimento aos restaurantes e lanchonetes do município, que comercializam grande volume de suco natural (dados não avaliados). A tangerina poncã é um caso particular, pois obteve apenas $140 \mathrm{~kg}$ de consumo semanal e isso não pôde ser explicado pelo seu preço, que foi bastante acessível (Tabelas 1 e 2), porém a causa não foi estudada. A maçã, apesar de ter sido classificada como quarta fruta mais cara ao consumidor, ficou em segundo lugar no consumo, isso porque boa parte do volume comercializado é oriunda de maçãs de menor calibre, chamadas na região de "maçanzinhas" e, conseqüentemente, de menor preço. Não foi estudado o efeito proporcional entre volume e preço para cada fruta neste trabalho.

A feira-livre foi responsável por $9,7 \%$ do volume de frutas comercializado, considerando-se a média dos equipamentos, e por 2,7\% no total (Tabela 2), sendo esses índices importantes para expressar a pequena participação deste varejo no comércio de frutas em Mineiros. $\mathrm{O}$ fato de a feira-livre funcionar apenas nas manhãs de domingo e a pouca quantidade e diversidade de produtos frutícolas podem ser fatores que explicam a baixa participação deste equipamento no comércio de frutas em Mineiros. Isso pode ser reflexo da incipiente participação de propriedades rurais locais no fornecimento de frutas aos mercados mineirenses, pois revelaria a falta de pomares comerciais no município e adjacências, já que a feira-livre tem como característica básica a comercialização de agroalimentos produzidos nas propriedades rurais e áreas vizinhas, ou seja, quando não há oferta de certa categoria de produtos agropecuários, pode ser indício de que também não há produção comercial destes nas proximidades. Neste tocante, fica caracterizada a necessidade de se desenvolver o setor frutícola na região e, ao mesmo tempo, ser encarado como uma opção para investimentos. Conforme Silva et al. (2003), o feirante tem como uma das características a realização de compras diretas do produtor (às vezes é a mesma pessoa).

A comprovação de que Mineiros e regiões próximas são incapazes de abastecer o mercado interno de frutas, ficou evidenciada quando se obteve uma participação de $80,1 \%$ do 
Ceasa-GO (Goiânia-GO, a 420 km de Mineiros), no fornecimento destes produtos ao município (Tabela 4), sendo necessário, às vezes, vencer distâncias maiores para adquirir o produto desejado, pois $13,2 \%$ das frutas consumidas originaram-se do Ceasa-SP. A fraca participação de produtores locais no fornecimento de frutas ao mercado varejista (apenas 6,7\%) pode ser encarada como indício da incipiente expressão do agronegócio da fruticultura da região.

Os varejistas de Mineiros precisam ficar atentos às possibilidades de flexibilização das margens de comercialização, pois os resultados obtidos revelaram acentuada discrepância entre as margens praticadas nos mercados, o que não é muito desejável, pois um melhor equilíbrio nas margens de lucro poderia favorecer maior consumo de determinadas frutas pelo simples fato de seus preços sofrerem diminuição como resultado do nivelamento das margens de comercialização. Rangel et al. (2003) destacaram a importância do preço na preferência por determinadas frutas pelos consumidores.

As informações obtidas no presente trabalho são de considerável relevância para os mercados varejistas do município de Mineiros, pois dão uma idéia do consumo semanal de frutas, relacionando-o com o preço praticado nos mercados atacadista e varejista, possibilitando, por exemplo, que um equipamento possa aumentar suas vendas de determinadas frutas mediante preços mais acessíveis obtidos por melhor equilíbrio na distribuição das margens de comercialização, incentivando assim maior consumo de frutas pela população. É importante ainda ressaltar que os resultados não obtiveram participação das frutas típicas de cerrado nos equipamentos entrevistados, o que torna evidente a necessidade de se valorizar estes produtos como forma não só de se criar uma alternativa de renda para o produtor da região, mas também como forma de incentivo à preservação da vegetação remanescente e à implantação de novos povoamentos. O comércio de frutas de cerrado em Mineiros é informal e, popularmente, é considerado como importante para o município.

Os dados ainda revelaram uma fraca participação da fruticultura local no mercado do município abordado, fato este que confirma a carência desta atividade na região. Por outro lado, essa situação pode ser encarada como incentivo à idealização e implementação de programas de desenvolvimento do agronegócio da fruticultura, pois, se há falta, há a necessidade de se criar oferta.

TABELA 1. Volume semanal de frutas comercializadas em Mineiros-GO. ICA/Fimes, Mineiros-GO.

\begin{tabular}{|c|c|c|c|c|c|c|c|c|c|c|c|c|}
\hline \multirow[t]{3}{*}{ Ranking } & \multicolumn{9}{|c|}{ Equipamento } & \multirow{2}{*}{\multicolumn{3}{|c|}{ Geral }} \\
\hline & \multicolumn{3}{|c|}{ Supermercados } & \multicolumn{3}{|c|}{ Quitandas/Sacolões } & \multicolumn{3}{|c|}{ Feira-livre } & & & \\
\hline & Fruta & Vol ${ }^{(a)}$ & $\%^{(b)}$ & Fruta & Vol & $\%$ & Fruta & Vol & $\%$ & Fruta & Vol & $\%$ \\
\hline $1^{\circ}$ & Laranja & 593,3 & 42,0 & Laranja & $1.175,0$ & 39,0 & Abacaxi & 375,0 & 78,9 & Laranja & 7.196 & 40,1 \\
\hline $2^{\circ}$ & Maçã & 265,3 & 18,8 & Maçã & 360,0 & 12,0 & Taiti & 100,0 & 21,1 & Maça & 2.812 & 15,7 \\
\hline $3^{\circ}$ & Banana & 193,3 & 13,7 & Banana & 490,0 & 16,3 & & & & Banana & 2.526 & 14,1 \\
\hline $4^{\circ}$ & Taiti & 120,0 & 8,5 & Abacaxi & 375,0 & 12,5 & & & & Abacaxi & 1.935 & 10,8 \\
\hline $5^{\circ}$ & Abacaxi & 101,3 & 7,2 & Mamão & 450,0 & 14,9 & & & & Mamão & 1.473 & 8,2 \\
\hline $6^{\circ}$ & Mamão & 55,4 & 3,9 & Uva & 67,5 & 2,2 & & & & Taiti & 1.060 & 5,9 \\
\hline $7^{\circ}$ & Uva & 46,3 & 3,3 & Poncã & 50,0 & 1,7 & & & & Uva & 515 & 2,9 \\
\hline $8^{\circ}$ & Pêra & 25,5 & 1,8 & Pêra & 15,0 & 0,5 & & & & Pêra & 234 & 1,3 \\
\hline $9^{\circ}$ & Nectarina & 7,0 & 0,5 & Maracujá & 18,0 & 0,6 & & & & Poncã & 140 & 0,8 \\
\hline $10^{\circ}$ & Poncã & 5,0 & 0,4 & Manga & 10,0 & 0,3 & & & & Nectarina & 56 & 0,3 \\
\hline $\begin{array}{l}\text { VTm } \\
(\%)\end{array}$ & & $\begin{array}{c}1.412,1 \\
28,8 \\
\end{array}$ & 100,0 & & $\begin{array}{c}\mathbf{3 . 0 1 0 , 5} \\
61,5 \\
\end{array}$ & 100,0 & & $\begin{array}{c}475,0 \\
9,7 \\
\end{array}$ & 100 & & $\begin{array}{c}\mathbf{1 7 . 7 9 3} \\
100 \\
\end{array}$ & 100 \\
\hline $\begin{array}{l}\text { VTg } \\
(\%)\end{array}$ & & $\begin{array}{c}11.297,0 \\
63,5 \\
\end{array}$ & & & $\begin{array}{c}\mathbf{6 . 0 2 1}, \\
33,8\end{array}$ & & & $\begin{array}{c}475,0 \\
2,7 \\
\end{array}$ & & & 100 & \\
\hline
\end{tabular}

(a) Volume médio comercializado pelos equipamentos em kg; (b) Porcentagem relativa de participação de cada fruta no volume total comercializado; VTm: Volume Total médio por equipamento; VTg: Volume Total geral dos equipamentos.

TABELA 2 - Preços no atacado e varejo das principais frutas frescas comercializadas nos equipamentos de Mineiros-GO. ICA/Fimes, Mineiros-GO.

\begin{tabular}{|c|c|c|c|c|c|c|}
\hline \multirow[t]{2}{*}{ Ranking } & \multirow[t]{2}{*}{ Fruta $^{\text {(a) }}$} & \multicolumn{2}{|c|}{$\mathbf{R} \mathbf{S}^{(b)}$} & \multirow[b]{2}{*}{$\left(R \$ k g^{-1}\right)$} & \multirow{2}{*}{$\begin{array}{c}\text { Margem do Varejo } \\
(\%)\end{array}$} & \multirow{2}{*}{$\begin{array}{c}\text { Margem de Lucro } \\
\text { no Varejo (\%) }\end{array}$} \\
\hline & & Atacado $^{(\mathrm{c})}$ & Varejo $^{(\mathrm{d})}$ & & & \\
\hline $1^{\circ}$ & Nectarina & 3,90 & 5,92 & 2,02 & 34,1 & 51,7 \\
\hline $2^{\circ}$ & Uva & 3,43 & 4,96 & 1,53 & 30,8 & 44,4 \\
\hline $3^{\circ}$ & Pêra & 2,58 & 3,99 & 1,41 & 35,3 & 54,5 \\
\hline $4^{\circ}$ & Maçã & 2,26 & 3,23 & 0,97 & 30,1 & 77,1 \\
\hline $5^{\circ}$ & Mamão & 1,09 & 1,94 & 0,85 & 43,5 & 43,1 \\
\hline $6^{\circ}$ & Banana & 1,24 & 1,80 & 0,56 & 30,7 & 44,4 \\
\hline $7^{\circ}$ & Taiti & 0,67 & 1,76 & 1,09 & 61,7 & 161,2 \\
\hline $8^{\circ}$ & Poncã & 1,25 & 1,51 & 0,26 & 16,7 & 20,0 \\
\hline $9^{\circ}$ & Abacaxi & 1,03 & 1,46 & 0,43 & 29,0 & 40,8 \\
\hline $10^{\circ}$ & Laranja & 0,94 & 1,33 & 0,39 & 28,8 & 40,4 \\
\hline
\end{tabular}

$\Delta$ : Diferença absoluta entre preço no varejo e preço no atacado para cada fruta $\left(\Delta=\mathrm{P}_{\mathrm{var}}-\mathrm{P}_{\text {tac }}\right)$. (a) Ordenação conforme preço no varejo; (b) Preço corrigido pelo IGP-DI mediante fator de correção do mês de maio, no ano, conforme dados do IEA (2006); (c) Preço médio de compra nos fornecedores em $\mathrm{R} \$ \mathrm{~kg}^{-1}$;

(d) Preço médio de venda ao consumidor em $\mathrm{R} \$ \mathrm{~kg}^{-1}$. 
TABELA 3 - Coeficientes de correlação simples entre volume de frutas comercializado semanalmente e o preço praticado no varejo. ICA/Fimes, Mineiros-GO, 2006.

\begin{tabular}{ccc}
\hline Parâmetros & Coeficiente de correlação & Probabilidade $>\mathbf{t}^{(\mathbf{1})}$ \\
\hline Volume frutas $\times$ Preço varejo & $-0,48$ & 0,02664 \\
Preço atacado $\times$ Preço varejo & 0,98 & 0,00055 \\
\hline
\end{tabular}

(1) $\mathrm{P}>0,05$

TABELA 4 - Principais fornecedores de frutas comercializadas semanalmente nos equipamentos varejistas de Mineiros-GO. ICA/Fimes, Mineiros-GO.

\begin{tabular}{lccc}
\hline Ranking & Fornecedores & Volume (kg) & \% Relativa de participação \\
\hline $1^{\circ}$ & Ceasa-GO & $14.827,6$ & 80,1 \\
$2^{\circ}$ & Ceasa-SP & $2.448,0$ & 13,2 \\
$3^{\circ}$ & Produtores Locais & $1.229,0$ & 6,7 \\
Total & & $\mathbf{1 8 . 5 1 0 , 6 ^ { ( a ) }}$ & $\mathbf{1 0 0}$ \\
\hline
\end{tabular}

(a) Somatório das dez principais frutas comercializadas em Mineiros (17.947 $\mathrm{kg})$ e das demais frutas $(563,6 \mathrm{~kg})$.

\section{CONCLUSÕES}

Nas condições em que o presente trabalho foi conduzido, conclui-se que em Mineiros-GO:

1-As frutas tropicais e subtropicais têm preferência de consumo, talvez devido à sazonalidade e aos menores preços no varejo.

2-Os supermercados são predominantes no volume de frutas comercializado.

3-Proporcionalmente, as quitandas são importantes para a comercialização de frutas.

4-O mercado de frutas possui um comportamento uniforme e é dependente do abastecimento a longas distâncias, que pode ser indício de necessidade de se desenvolver a fruticultura local.

\section{REFERÊNCIAS}

BUENO, C.R; REIS, R.P.; SOUZA, M. de. Estudo mercadológico da sazonalidade de frutos cítricos ofertados no município de Lavras-MG. Ciência e Agrotecnologia, Lavras, v.23, n.4, p.813824, out./nov. 1999.

AUTOR. Título do artigo. Jornal Diário da Manhã, Goiânia, 7, abril, 2004. Caderno de Economia.

FAGUNDES, G.R.; YAMANISHI, O.K. Estudo da comercialização do mamão em Brasília-DF. Revista Brasileira de Fruticultura, Jaboticabal, v.24, n.1, p.091-095, 2002.

GOIAZ, A. Cerrado com frutas temperadas. Jornal Diário da Manhã, Goiânia, 7, abril, 2004. Caderno de Economia.

INSTITUTO BRASILEIRO DE ECONOMIA. Economia e gestão: indicadores econômicos. Rio de Janeiro: IBRE/Fundação Getúlio Vargas. Disponível em: < http://www2.fgv.br/dgd/asp/ index.asp $>$. Acesso em: 13 jun. 2006.

INSTITUTO BRASILEIRO DE GEOGRAFIA E ESTATÍSTICA.
Pesquisa de Orçamentos Familiares 2002-2003: aquisição alimentar domiciliar per capita. Brasília: IBGE/Diretoria de Pesquisas/Coordenação de Índices de Preços, Pesquisa de Orçamentos Familiares 2002-2003. (Tabela 1.1). Disponível em: <http:/www.ibge.gov.br/home/estatistica/populacao/ condicaodevida/pof/2002aquisicao/tab11.pdf>. Acesso em: 13 jun. 2006.

LOURENZANI, A.E.B.S.; SILVA, A.L. da. Um estudo da competitividade dos diferentes canais de distribuição de hortaliças. Gestão e Produção, São Carlos, v.11, n.3, p.385398, 2004.

RAMOS, J.D.; PIO, R.; MENDONÇA, V. Situação da fruticultura no município de Lavras-MG. Ciência e Agrotecnologia, Lavras, p.1594-1598, d 2002. Edição Especial.

RANGEL, S.B.; FAGUNDES, G.R.; FALCÃO, T.C.C.; M. de S.M.; YAMANISHI, O.K. Perfil do mercado varejista e consumidor de mamão dos grupos 'solo' e 'formosa' do Distrito FederalDF. Revista Brasileira de Fruticultura, Jaboticabal, v.25, n.1, p.85-88. abr. 2003.

SILVA, C. de S.; PEROSA, J.M.Y.; RUA, P.S.; ABREU, C.L.M. de; PÂNTANO, S.C.; VIEIRA, C.R.Y.I., BRIZOLA, R.M. de O. Avaliação econômica das perdas de banana no mercado varejista: um estudo de caso. Revista Brasileira de Fruticultura, Jaboticabal, v.25, n.2, p229-234, ago. 2003

SOUZA, J.M.G. de. Fruticultura (I): uma visão geral do mercado. Fortaleza: Rede de Irrigação, 2006. 11p. (Documento, 1). 


\section{ERRATA}

Revista Brasileira de Fruticultura, vol 29, n. 2, p. 282-286.

FOLHA: Página 284 - RESULTADOS E DISCUSSÃO - $1^{\circ}$ parágrafo

Onde se lê:

"(Diário da Manhã, 2004)"

Leia-se:

"(Goiaz, 2004)".

FOLHA: Página 286 - REFERÊNCIAS

Onde se lê:

AUTOR. Título do artigo. Jornal Diário da Manhã *, Goiânia, 7,abril , 2004.Caderno de Economia.

Leia-se:

GOIAZ, A. Cerrado com frutas temperadas. *Jornal Diário da Manhã*, Goiânia,7,abril, 2004. Caderno de Economia. 
O arquivo disponível sofreu correções conforme ERRATA publicada no Volume 29 Número 3 da revista. 